\title{
The Nature of Indeterminate Expressions in Chinese \\ and Korean: Focused on Wh-phrases in Conditionals
}

Daeho Chung ${ }^{1}$ \& Myung-Kwan Park ${ }^{2+}$

${ }^{1}$ Hanyang University, ${ }^{2}$ Dongguk University

\begin{abstract}
In this paper, we argue that indeterminates in so-called bare wh-conditionals of Chinese are not ordinary indefinites but wh-indefinites. Thus, they are subject to overt ATB-fashion wh-movement, with its tail copy ultimately being realized rather than being licensed via unselective binding by the universal operator, as proposed in Cheng and Huang (1996). We ascribe the co-varying interpretation between the two wh-indefinites in the two antecedent and consequent clauses to the property of the covert form of subordinate conjunction, which can only unify identically interpreted conjoined elements. On the other hand, Korean $w$-indefinites are not subject to overt wh-movement but enter into Agree with the $\mathrm{Q}$ marker for their licensing. Thus, in the Korean counterpart of bare wh-conditionals, the wh-indefinite in the antecedent clause is referred back to by the anaphoric expression in the subsequent clause that serves as an E-type pronoun, such as a demonstrative (plus the $w h$-indefinite) or a null argument. It is to be underscored that, owing to the lack of overt wh-movement, the two wh-indefinites in Korean cannot be anaphorically linked via ATB wh-movement.
\end{abstract}

Keywords: indeterminates, bare wh-conditional, (c)overt wh-movement, ATB whmovement, co-varying, subordinating conjunction

\section{Introduction}

It is generally accepted that both Chinese and Korean are wh-in-situ languages, and wh-phrases in the two languages are ambiguously interpreted, that is, either as an interrogative wh-expression or an indefinite expression. This is why these

\footnotetext{
* Previous versions of the paper have been presented on several occasions: Transdisciplinary Approaches to Language Variation (TALV) Workshop 2, Cyprus University of Technology, Cyprus, Feb 15 16, 2019; International Conference on Korean Linguistics (ICKL) 2019, Monash University, Australia, Jul 10 11 2019; and Asian GLOW 2019, Dongguk University, Seoul, Aug 7 10, 2019. We appreciate comments and suggestions at the conferences and workshop. Special thanks go to Hee-Don Ahn, Min-Joo Kim, Sun-Woong Kim, Bum-Shik Park, Jong-Un Park, Mamoru Saito, and Borui Zhang for valuable discussions. We are also grateful to three anonymous reviewers of this journal for the constructive suggestions and feedback. The usual disclaimers apply, of course.

† Corresponding author: parkmk@dongguk.edu
} 
expressions are often called indeterminate expressions. In the current work, we study the featural properties and the licensing mechanisms of such indeterminate expressions in the two languages, comparing their behaviors mainly in conditional constructions and furthermore in wh-constructions in general.

We are going to make the following claims. First, contra the generally accepted view, Chinese indeterminate expressions (at least sometimes) undergo overt movement to be licensed as [+wh] interrogative elements (cf. Cheng \& Huang, 1996; Liu, 2016, 2018a, 2018b; Huang, 2018), while the Korean counterparts remain in situ and get licensed via Agree (cf. Tsai, 1994; Watanabe, 1992; Saito, 2017). Second, Chinese indeterminate expressions in wh-conditionals undergo ATB wh-movement (cf. Bruening \& Tran, 2006; Cheung, 2006). Third, indeterminate expressions in Chinese move, but the tail of the chain gets pronounced. So we argue that Korean is a genuine wh-in-situ language, while Chinese is not: Chinese behaves more like English in some important respects.

\section{Chinese Wh-conditionals and Their Korean Counterparts}

As in the examples of (1), Chinese has an interesting conditional construction, called bare conditionals (Cheng and Huang, hereafter C \& H, 1996) or wh-conditionals (Liu, 2016, 2018a, 2018b; Huang, 2018), that lacks subordinator IF.

$\begin{array}{llll}\text { (1) a. shei } & \text { xian lai, } & \underline{\text { shei (jiu) }} & \text { xian chi. } \\ \text { Who first come, } & \text { who (then) } & \text { first eat }\end{array}$

'(If) x comes first, (then) $\mathrm{x}$ eats first.' ='Whoever comes first eats first.'

b. ni yao shenme, wo (jiu) mai shenme gei ni.

You want what, I (then) buy what give you

'(If) you want $\mathrm{x}$, (then) I will buy $\mathrm{x}$ for you.'

'Whatever you want, I will buy it for you.'

Two identical forms of wh-expressions appear both in the antecedent and the consequent clauses. Since C \& H (1996), a considerable volume of literature has discussed the construction. The two (i.e., one in the antecedent clause and the other in the consequent clause of the construction) are interpreted as if they are variables bound by the same operator such that they co-vary in their reference, as indicated in the English translations.1) 
C \& H (1996) claim that Chinese bare wh-conditionals bear an implicit necessity operator just as English conditionals do (Heim, 1982) and that both indeterminate expressions in bare conditionals are unselectively bound by the null universal quantifier, as schematically represented below:

(2) $\forall \mathrm{x} \cdot \mathrm{P}(\mathrm{x}) \rightarrow \mathrm{Q}(\mathrm{x})$

They also claim that, when the subordinator is overtly realized like ruguo, the conditional takes an E-type pronoun licensing pattern that is realized as an overt pronoun or a covert pronoun (pro), as exemplified in (2) below.

(3) ruguo ni kandao shei, quing jiao $\left\{{ }^{*}\right.$ shei/ta/[e]\} lai jian wo if you see who please tell who/him/pro come see me 'If you see someone, please ask him/her to come see me.'

(modified from C \& H, 1996: 127, their $(23 a \sim c)$ )

They claim that this type of construction with a wh-word in the consequent clause is ungrammatical, while the one either with overt pronoun ta or with pro in it is well-formed.

Cheung (2007) reports, however, attributing the observation to Leung (2006) and Pan \& Jiang (2015), that in the bare wh-conditionals the wh-indeterminate in the consequent clause can be phonologically suppressed, contra C \& H (1996):

(4) (=Cheung, 2007, p. 151, her (3))

a. shei xiang qu Beijing, [e] dei/bixu/yiding-yao dao wo zheli baodao. who want go must to me here register 'If $\mathrm{X}$ wants to go to Beijing, $\mathrm{X}$ must register with me.'

1) Contra C \& H (1996), Gu (2009) reports that wh-conditionals can have a definite reading in addition to the universal reading, as in the example in (i) below.

(i) nei (yi) ben shu dazhe, zhangsan jiu hui mai nei (yi) ben shu. which one CL book on-sale Zhangsan then will buy which one CL book 'Zhangsan will buy the book that is on sale.'/ 'Zhangsan will buy whichever book is on sale.'

In a context where a unique reference can be established, (i) picks out the unique on-sale book and is a felicitous answer to a wh-question ('which one of these books is Zhangsan going to buy?'). 
b. shei xian qu Beijing, [e] qing dao wo zheli baodao. who want go please to me here register 'If X wants to go to Beijing, please register with me.'

c. shei xihuan shei, shei yinggai shuo chulai. who like who who should say out 'If X likes $\mathrm{Y}, \mathrm{X}$ should voice out.'

As pointed out by Cheung (2007), the above data cannot be easily accounted for by unselective binding analyses. Furthermore, Pan \& Jiang (2015) report that IF (ruguo/yaoshi) conditionals may host a wh-indeterminate in the consequent clause at least in certain contexts. $\left.{ }^{2}\right)$

(5) (=Pan \& Jiang, 2015, p. 165, their (7))

a. ruguo shei yao zhe po-chang, jiu rang shei
if who want this broken-factory then let who
dao bangongshi lai zhao wo.
to office come find me

'Whoever wants this broken factory, let him/her come to my office to see me.'

b. hai shuo: Xiangshan meiyou liangpian xiangtong de hongye, also say not-have two same DE maple-leave ruguo shei zhaodao le, shei jiu shi zui xingfu de ren. if who find PERF who then be most happy DE person 'Also said: there are no two maple leaves in Xiangshan that are exactly the same. If anyone/someone finds them, then s/he will be the happiest person.'

(6) (=Pan \& Jiang, 2015, pp. 166-167, their (9))

a. shei yaoshi fandui ta, shei jiu shi women de diren. who if against him who then be our DE enemy '(If) Whoever is against him, then s/he will be our enemy.'

2) As will be discussed presently, unlike in (5) and (6) of Chinese, their counterparts of Korean do not allow the two wh-phrases in the antecedent and consequent clauses to co-vary. 
b. yaoshi shei neng faming yizhong dianshixinxi caiji de diannao, if whocan invent one-CL TV information collect DEcomputer wo hui gei ta yi-da-bi qian. I will give him/her a-large-lump-sum money

'Whoever can invent a kind of computer that collects information from TV broadcasting, I will give him/her a large lump sum of money.'

Now let us see how wh-indeterminate expressions behave in Korean conditionals. Direct or literal translations of (1a) and (1b) into Korean do not convey a co-variant reading. For example, the two instances of nwu-ka in (7a) or of mwues-ul in (7b) do not refer to the same entities.

(7) a. nwu-ka mence o-myen, nwu-ka mence mek-nun-ta.

Who-Nom early come-if, who-Nom early eat-Pres-DEC

'(If) someone comes first, (then) someone eats first.'

b. (ney-ka) mwues-ul wenha-myen, nay-ka mwues-ul sacwu-keyss-ta. You-Nom what-Acc want-if I-Nom what-Acc buy;give-will-DEC 'If you want something, I will buy something for you.'

To get the intended co-varying reading, the wh-indeterminate in the consequent clause has to be suppressed or replaced by an overt/null pronoun, as in (8).

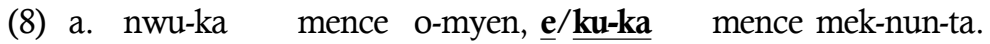
Who-Nom early come-if, e/he-Nom early eat-Pres-DEC '(If) someone comes first, (then) someone eats first.'

b. (ney-ka) mwues-ul wenha-myen, nay-ka e/kukes-ul sacwu-keyss-ta.

You-Nom what-Acc want-if I-Nom e/it-Acc buy;give-will-DEC 'If you want something, I will buy something for you.'

In this sense, Korean conditionals behave more like ruguo or yaoshi conditionals in Chinese, but, not exactly because Korean conditionals never allow wh-indeterminates with a co-varying reading.

So the issue is why (bare) wh-conditionals in Chinese, but not in languages like Korean, require/allow (depending on the speakers, e.g. Cheng \& Huang, 1996 vs. Pan \& Jiang, 2015) the isomorphic forms of co-variant wh-indeterminates in the antecedent and the consequent clauses. 


\section{Some Other Relevant Variations between Chinese vs. Korean}

Before providing our proposals, we discuss some more relevant variations between the two languages in section 3 .

\subsection{Wh-conditionals and the novelty condition}

First, we discuss the facts in relation to the so-called Novelty Condition. As noted in the literature, C\&H's (1996) indefinite analysis of wh-indeterminates faces a problem with the Novelty Condition, which states that indefinite NPs must not have the same referential index as any NP to its left, as in (9).

(9) The Novelty Condition (Heim, 1982)

Indefinite NPs must not have the same referential index as any NP to its left.

To circumvent the novelty condition problem, Chierchia (2000) proposes an Indefinite Pronoun Analysis of the wh-indeterminate in the consequent clause. Note that a pronoun can be used as a discourse anaphor, as in the example in (10), where indefinite expression a man in the consequent clause cannot, but pronoun he can, be anaphoric to a man in the antecedent clause.

(10) If a $\operatorname{man}_{\mathrm{i}}$ comes first, $\left\{{ }^{*} \mathrm{a} \operatorname{man}_{\mathrm{i}} / \mathrm{h} \mathrm{e}_{\mathrm{i}}\right\}$ eats first.

As pointed out by Bruening \& Tran (2006) and Crain \& Luo (2011), however, wh-indeterminates are subject to Binding Theory $(\mathrm{BT})(\mathrm{C})$, not to BT(B), as shown in the following examples:3)

(11) (=Bruening \& Tran, 2006, their (10))

a. shei yaoshi shuo $t a /{ }^{*}$ shei xihuan wo meimei, wo jiu zou shei. who if say he/*who like mysister I then hit who 'If $\mathrm{X}$ says that he likes my sister, I hit X.'

b. shei yaoshi jinlai bu qiaomen, wo jiu gaosu shei ta/*shei hen lumang. who if enter Neg knock I then tell who he/*who very rude 'If $\mathrm{X}$ enters without knocking, I tell $\mathrm{X}$ that he's very rude.'

3) One might argue that these sentences are irrelevant, because the existence of yaoshi rules out the possibility that these sentences are not bare wh-conditionals. Notice, however, that $w h$-indeterminates are present both in the antecedent and consequent clauses. 
As shown in the examples in (11), wh-indeterminate expressions cannot be bound by the same form of $w h$-indeterminates, neither in the antecedent clause nor in the consequent clause. Thus they conclude that wh-phrases in Chinese are not pronouns, but they rather stand as R-expressions.

By contrast, Korean wh-indeterminates are subject to the Novelty Condition. For example, wh-phrases in the consequent clauses in (7), repeated below, do not have an anaphoric interpretation.

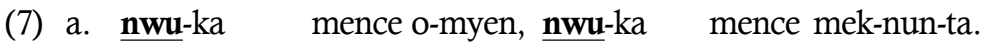
who-Nom early come-if, who-Nom early eat-Pres-DEC '(If) someone comes first, (then) someone eats first.'

b. (ney-ka) mwues-ul wenha-myen, nay-ka mwues-ul sacwu-keyss-ta. you-Nom what-Acc want-if I-Nom what-Acc buy;give-will-DEC 'If you want something, I will buy something for you.'

These examples show that unlike their counterparts in Chinese, wh-indeterminate expressions in Korean are subject to the Novelty Condition, and they behave like indefinite expressions. ${ }^{4}$

According to Cheung (2007), the same is true in Chinese, when the wh-indeterminate expressions in bare wh-conditionals are replaced by their counterpart indefinite NP's, as shown in (12). Note that the two occurrences of yi-ge nanren in the example cannot refer to the same person.

(12) (=Cheung, 2007, p. 152, her (9))

* ni xihuan yi-ge nanren, wo jiu da yi-ge nanren i. $_{\text {. }}$

you like one-CL man I then hit one-CL man

(Intended) 'If you like a $\operatorname{man}_{\mathrm{i}}$, I hit himi.'

4) Jong-Un Park (pers. comm.) provides the following example, which appears to produce a co-varying reading of the wh-phrases:

(i) [nwukwu-tunci mence o-myen], [nwukwu-tunci mence mek-nun-ta] who-ever early come-if who-ever early eat-Pres-Ded (Lit.) 'Whoever comes first, whoever eats first.'

We note, however, that a pronoun or a definite description can mediate the relation of the two universal-like wh-phrases, as follows:

(ii) [nwukwu-tunci mence o-myen], [ $\{\mathrm{ku}-\mathrm{ka} / \mathrm{ku}$ salam-i $\}$ nwukwu-tunci mence mek-nun-ta] who-ever early come-if he-Nom/that person-Nom who-ever early eat-Pres-Ded (Lit.) 'Whoever comes first, he/that person, whoever it is, eats first.'

Thus the apparent co-varying reading in (i) is not caused by repetition of the two wh-phrases, but rather by an E-type pronoun strategy. 
By contrast, at least some set of bare nominals in Korean are not subject to the Novelty Condition. Consider the following examples, where the underlined bare nominals may refer to the identical entities.5)

(13) a. Cheli-ka catongcha-ul wenha-myen, Ch.-Nom car-Acc want-if

(kulem) nay-ka catongcha-ul sacwu-keyss-ta.

then I-Nom car-Acc buy;give-will-Dec

'If Cheli wants a car, I will buy (him) (a/the) car.'

b. nongpwu-ka tangnakwui-lul kaci-myen, farmer-Nom donkey-Acc have-if nongpwu-ka pothong tangnakwui-lul ttayli-n-ta. farmer-Nom usually donkey-Acc beat-Pres-Dec

'If a farmer has a donkey, (the) farmer usually beats (the) donkey.'

c. phyenci-ka o-myen, apeci-ka mence phyenci-lul ilk-nun-ta. letter-Nom come-if father-Nom early letter-Acc read-Pres-Dec 'If a letter arrives, Father reads the letter first."

d. haksayng-i mence o-myen, haksayng-i mence mek-nun-ta. student-Nom early come-if student-Nom early eat-Pres-Dec If a student comes first, (the) student eats first.'

When accompanied by a numeral classifier, however, the resulting indefinite nominals do not co-vary, as shown in (14), where a floating numeral quantifier is associated with the preceding nominals. Pre- or post-nominal numeral classifiers seem to behave in the same way, as we see in the examples of (15).

$\begin{array}{llll}\text { apeci-ka } & \text { chayk-ul } & \text { han kwen } & \text { sacwu-myen, } \\ \text { father-Nom } & \text { book-Acc } & \text { one CL } & \text { buy-if } \\ \text { Cheli-ka } & \text { chayk-ul } & \text { han kwen } & \text { ilk-nun-ta. } \\ \text { Ch.-Nom } & \text { book-Acc } & \text { one CL } & \text { read-Pres-Dec } \\ \text { 'If his father buys (him) a book, Cheli reads a (different) book.' } \\ \text { \#'If his father buys (him) a book, Cheli reads the book.' }\end{array}$

5) Refer to Park (2019) for the distinct anaphoric definite use of bare nominals and numeral classified nominals in Korean and Chinese. 
$\begin{array}{ll}\text { b. haksayng-i han myeng mence } & \begin{array}{l}\text { o-myen, } \\ \text { student-Nom one CL early }\end{array} \text { come-if }\end{array}$ haksayang-i han myeng sang-ul pat-nun-ta. student-Nom one CL reward receive-Pres-Dec 'If a student comes first, a student receives a prize.' \#'If a student comes first, the student receives a prize.

(15) a. apeci-ka \{han kwen-uy chayk-ul/chayk han kwen-ul $\}$ sacwu-myen, father-Nom one CL-Gen book-Acc/book one CL-Acc buy-if Cheli-ka \{han kwen-uy chayk-ul/chayk han kwen-ul\} ilk-nun-ta. Ch.-Nom one CL-Gen book-Acc/book one CL-Acc read-Pres-Dec 'If his father buys (him) a book, Cheli reads a (different) book.' \#'If his father buys (him) a book, Cheli reads the book.'

b. \{han myeng-uy haksayng-i/haksayng han myeng-i $\}$ mence o-myen, one CL-Gen student-Nom/student one CL-Nom early come-if $\{$ han myeng-uy haksayng-i/haksayng hanmyeng-i\} sang-ul pat-nun-ta. one CL-Gen student-Nom/student oneCL-Nom reward receive-Pres-Dec 'If a student comes first, a student receives a prize.' \#'If a student comes first, the student receives a prize.'

To avoid the Novelty Condition problem, Crain and Luo (2001) propose that bare wh-conditionals are sort of an equational statement, citing examples like (16), where the post-copula nominal is an indefinite expression, but does not suffer from the Novelty Condition.

(16) (=Crain \& Luo, 2011, p. 172, their (16))

A man who drinks alcopops is a man who gets a hangover.

The equation sentence is indeed immune from the novelty condition, and this analysis may account for the novelty condition problem.

There is some discrepancy, however, between bare conditionals and equational statements. Notice that Chinese bare wh-conditionals must contain isomorphic wh-indeterminates in the antecedent and consequent clauses.

(17) (adopted from Crain \& Luo, 2011, p. 166, their (3)) shei xian lai, $\left\{\underline{\text { shei }}{ }^{*}\right.$ shenme ren/* tongyang de ren $\}$ xian chi. who first come who/ what person/the-same DE person first eat 
The antecedent clause in (17) contains wh-indeterminate shei 'who'. So the consequent clause should also contain shei. Expressions like shenme ren 'what person' and tongyang de ren 'the same person' are not allowed, even if they are semantically very close to shei. In contrast, isomorphic forms are not required in equational statements, as exemplified below.

(18) a. The Morning Star is the Evening Star.

b. A man who drinks alcopops is the one/the same person who gets a hangover.

In fact, equational statements sound tautological, if pre- and post-copula elements are exactly the same.

3.2. Distribution of WHY (and other exclusively interrogative expressions) in (bare) wh-conditionals

Another discrepancy between Chinese and Korean lies in the fact that adverbial adjunct WHY is allowed in Chinese wh-conditionals, whereas it is not in Korean conditionals. Compare (19) and (20) below.

(19) ni wishenme xihuan Zhangsan, wo jiu wishenme taoyan ta.

you why like $Z$. I then why dislike him

'The reason you like Zhangsan is the reason why I dislike him.'

(cited from Huang 2018)

$$
\begin{aligned}
& \text { (20) *ney-ka way John-ul cohaha-myen, } \\
& \text { you-Nom why J.-Acc like-if } \\
& \text { na-nun way/ku iyu-lo ku-lul silheha-n-ta. } \\
& \text { I-Top why/the reason-for he-Acc dislike-Pres-DEC } \\
& \text { '(Intended) The reason you like John is the reason why I dislike him.' }
\end{aligned}
$$

Unlike nominal wh-expressions, WHY in wh-in-situ languages is hardly used as an indefinite expression and is sensitive to syntactic islands. The reason $w h$-adverbial wishenme in Chinese is not different (Huang 1982). Nevertheless, it can appear in Chinese wh-conditionals, as shown in (19) above. This fact seems to indicate that WHY in the antecedent clause of a wh-conditional is licensed in conjunction with the isomorphic wh-element in the consequent clause. In contrast, the reason 
wh-adverbial way in Korean, which is also exclusively used as an interrogative expression, is hardly licensed in conditionals, regardless of the composition of the consequent clause, as shown in (16), due to an island constraint.6)

Like way, elama-(mankhum)-(i)na 'how much/many' is also exclusively used as an interrogative expression and it has to be licensed by a question ending. Unlike way, however, it is a nominal expression that can be licensed by Agree. Thus, when embedded under the antecedent clause of a conditional, it can be licensed by a question morpheme of the consequent clause, due to Agree, but not by a declarative sentence ending, as shown in (21). In contrast, nominal expression elma mankhum (, as opposed to elama-(mankhum)-(i)na,) can be indefinitely (as well as interrogatively) used and it can appear in the antecedent clause of a conditional, regardless of the sentence ending type of the consequent clause, as in (22).

(21) pro elma (mankhum)-(i)na

yeppu-n os-i-myen,

how;much amount-INA pretty closthes-Cop-if

pwumonimtul-i e/ku kes-ul \{sacwu-ni?/*sacwu-n-ta. parents-Nom e/it-Acc buy;give-QE/buy-Pres-DEC

R1: 'How much degree is it such that if they are that degree of pretty clothes, parents buy the clothes for the children?'

R2(Intended): \#If they are a certain degree of pretty clothes, parents buy them for the children.

(22)

$\begin{array}{ll}\text { pro elma } & \text { mankhum } \\ \text { how;much amount } & \text { yeppu-n os-i-myen, } \\ \text { pretty closthes-Cop-if }\end{array}$
pwumonimtul-i e/ku kes-ul \{sacwu-ni?/sacwu-n-ta. parents-Nom e/it-Acc buy;give-QE/buy-Pres-DEC

R1: 'How much degree is it such that if they are that degree of pretty clothes, parents buy the clothes for the children?'

R2: If they are a certain degree of pretty clothes, parents buy them for the children.'

\subsection{Bare nominals in donkey sentences}

Thirdly, there is a difference between Korean and Chinese bare nominals in the

6) We assume, following the tradition of Huang (1982), Choe (1987), and Nishigauchi (1986), that way undergoes LF movement to be licensed. Cf. Ko (2005) 
context of donkey sentences. When not modified by a demonstrative, bare nominals in Chinese cannot function as a donkey anaphor, as shown in (23). They can be replaced by a pronoun, but not by a null pronoun, as shown in (24). In contrast, bare nominals in Korean can serve as a donkey anaphor just like a definite description, a pronoun, or a null pronoun, as exemplified in (25).7)

(23) a. mei-ge you lüzi $i_{i}$ de nongfu dou hui da $\left[{ }^{*}\right.$ (na-tou) lüzi $i_{i}$ every-CL have donkey DE farmer all will beat THAT.DEM-CL donkey 'Every farmer who owns a donkey beats the donkey.'
b. *mei-ge you lüzi $i_{i}$ de nongfu dou hui da lüzi every-CL have donkey DE farmer all will beat donkey
'Every farmer who owns a donkey beats donkeys.'

(24) mei-ge you lüzi $i_{i}$ de nongfu dou hui da $\mathrm{ta}_{\mathrm{i}} /{ }^{*} \Phi_{\mathrm{i}}$ every-CL have donkey DE farmer all will beat *(it) 'Every farmer who owns a donkey beats it.'

(25) tangnakwui-lul kaci-n nongpwu-nun nwukwuna donkey-Acc have-Rel farmer-Top all $\{\mathrm{ku}$ tangnakwui-lul/tangnakwui-lul/ku kes-ul/ [pro]\} ttayli-n-ta that donkey-Acc/donkey-Acc/that thing-Acc/pro beat-Pres-Dec 'Every farmer who owns a donkey beats the donkey/it/'

With the bare nominal selected, (25) seems to be fully felicitous in a scenario, for example, where every farmer owns one and only one donkey, and he or she beats his or her own donkey. Thus, Korean bare nominals can be anaphorically used in donkey contexts, unlike the Chinese counterparts.

\section{Licensing Mechanisms for Wh-conditionals in Chinese and Korean}

As noted above, C\&H (1996) take a unselective binding approach to bare wh-conditionals in Chinese. But their approach faces several problems. First, it does

7) One of the reviewers does not agree that (25) conveys a co-variant reading with the bare nominal in the main clause of the donkey sentence. We believe, however, that a co-variant reading is available, at least in a certain context, as stated below. 
not account for the Korean counterparts of Chinese bare wh-conditionals. If the two wh-indeterminates in the antecedent and the consequent clauses were licensed via unselective binding by the universal operator or the $\mathrm{Q}$ morpheme, they would be predicted to co-vary, which is not the case in Korean.
a. cheli-ka mwues-ul sao-myen,
(Korean)
Ch.-Nom what-Acc buy-if
Yengi-ka mence $\left\{\mathrm{ku}\right.$ mwues-ul/ku kes-ul/ $\quad{ }^{*}$ mwues-ul/ $\left.\Phi\right\}$ mekepli-ni?
Y.-Nom early thatwhat/ that thing-Acc/ what-Acc/ $\Phi$ eat;away-Q
'What is it that if Cheli buys it, Yengi eats it away?'
b. mwues-ul khiwu-nun nongpwu-un nwukwuna \{ku mwues-ul/ku kes-ul/ what-Acc raise-Rel farmer-Top all \{that what/that thing-Acc/ ${ }^{*}$ mwues-ul $\left./ \Phi\right\} \quad$ ttayli-ni? what/-Acc/ $\Phi$ beat-Q
'(Lit.) What is it such that every farmer who raises it beats it?'

The requirement for the isomorphic forms of indeterminate in the antecedent and the consequent clause also constitutes another argument against the unselective binding approach, as unselective binding is not sensitive to the formal identity. The following data from Chinese makes a point:

(27) *shei xian lai, shenme ren / $\underline{\text { tongyang de ren }}$ xian chi. ${ }^{8)}$
who first come what person the-same DE person first eat

(taken from Crain \& Luo (2011, p. 166, their (3))

A third problem with the unselective binding approach has to do with the fact that Chinsese wh-indeterminate expressions and non-wh bare nominal indefinite expressions behave differently in bare wh-conditionals (cf. Saito 2017): Only the former expressions can have a co-variant reading, as was seen in the previous section.

We rather argue that wh-indeterminate expressions in bare $w h$-conditionals bear a sort of $w h$-features, thus turning out to be $w h$-phrases. Notice that wh-conditionals can occur in matrix or embedded question clauses, as in (28) below. For example,

8) When indeterminates occur in the subject position of the antecedent clause in ruguo 'if'-conditionals, they can be preceded by you 'have', indicating that they can have existential force, being construed as quantificational. However, those in the subject position of bare (i.e., ruguo-less) wh-conditionals cannot be preceded by you 'have'. Indeterminates in bare wh-conditionals are resistant to being interpreted as quantificational. 
(28a) is represented as denoting a matrix question in (28a)'.

(28) a. shei xian lai, shei jiu keyi xian chi ne?

(Chinese)

who first come who then can first eat $\mathrm{Q}$

'Who is the person $\mathrm{x}$ such that if $\mathrm{x}$ comes first, then $\mathrm{x}$ is allowed to eat first?'

b. Akiu xiang-zhidao [shei xian lai, shei jiu keyi xian chi].

A. want-know who first come who then can first eat

'Akiu wonders [who is the person $\mathrm{x}$ such that if $\mathrm{x}$ comes first, $\mathrm{x}$ is allowed to eat first]'. (taken from Tsai (1994: (32))

(28a)' $\mathbf{Q x}$ [x a person] Rs [s a situation] if $\mathrm{x}$ comes first in $\mathrm{s}, \mathrm{x}$ is allowed to eat first in $s$.

In fact, we advance the thesis that in Chinse, wh-indeterminates undergo overt wh-movement, with their tails pronounced. By contrast, in Korean their counterparts get licensed not via overt wh-movement, but via Agree. We presently bring forth three arguments supporting this thesis. The first argument concerns a universal WH-QP interaction. Longobardi (1987) notes that the wh-phrase extracted out of the wh-island cannot reconstruct at LF to the wh-island internal position, thus the wh-phrase always taking wide scope over the embedded universal QP.

(29) ??Who do you wonder whether every student saw $t$ at the rally? 'who' > 'every student'; *'every student' > 'who'

The same pattern of WH-QP interaction as in English holds in Chinese (30a-b), but not in Korean (31):

(30) a. Zhangsan xiangxin [mei-ge xuesheung mai-le na-ben shu de shuofa]? Z. believe every-CL student buy-Perf which-CL bookDE claim 'Lit. Zhangsan believes the claim that every student bought which book?' (Abe, 2017, p. 27)

b. Ni xiang-zhidao meigeren shi-bu-shi dou kandao shenme?

You want-know everyone be-not-be all saw what

'Lit. You wonder whether everyone saw what?' (Aoun \& Li, 1993, p. 84) 
(31) sensayngnim-un [namhaksayng motwu-ka (kakca) mwues-ul sa-ss-nunka] teacher-Top male-student all-Nom each what-Acc buy-Pst-Q al-ko sipheha-si-no??)

know-be-Q

'Lit. Does Cheli want to know whether every male student bought what?'

The second argument bolstering overt wh-movement in Chinese comes from the sensitivity of a wh-phrase to a negative weak island. For example, in (32) of German the intervening negative element precludes the wh-phrase in-situ from associating with the complementizer (or with the wh-phrase in its Spec), as represented schematically in (33):

(32) a.

$\begin{array}{lll}\text { *Wer hat niemanden wo angetroffen? } & \text { who has nobody } \\ \text { who where met }\end{array}$

b. Wer hat wo ${ }_{1}$ niemanden $t_{1}$ angetroffen? who has where nobody met 'Who didn't meet anybody where?' (Beck, 1996; Beck \& Kim, 1997)

(33) $*\left[\begin{array}{lllllllll}\ldots & w_{1} & \ldots & {[} & \ldots & \text { negative } & \mathbf{Q P} & \ldots & \left.\left[\begin{array}{llll}\ldots & \mathrm{t}_{1} & \ldots\end{array}\right]\right]\end{array}\right]$ L LF movement

The same pattern of behavior as in German is found with the wh-phrase in-situ in Korean as in (34a) versus (34b):

$$
\begin{aligned}
& \text { a. *amwuto mwues-ul sa-ci anh-ass-ni? } \\
& \text { anyone what-Acc buy-Nm not.do-Pst-Q } \\
& \text { 'What did on one buy?' } \\
& \text { b. mwues-ul amwuto } \mathrm{t}_{1} \text { sa-ci anh-ass-ni? } \\
& \text { what-Acc anyone buy-Nm not.do-Pst-Q } \\
& \text { 'What did no one buy?' }
\end{aligned}
$$

However, the apparently similar type of wh-phrase in-situ in Chinese is not subject to the negative island constraint, as follows:

9) The judgment of (31) is essentially attributed to Suh (2008), where it is claimed that unlike the question-embedding verb al- 'know', al-ko cip- 'want to know' as in (31) is not subject to the wh-island onstraint in Kyengsang Dialect of Korean. 
(35) a. meiyouren gan gen shei dajia?

Nobody dare with who fight

'Who does nobody dare to fight with?'

b. henshaoren gan gen shei dajia?

Few person dare with who fight

'Who do few people dare to fight with?' (Huang, 1982, pp. 263-267)

We argue that this difference between Chinse and Korean/German in regard to wh-phrases in-situ in their (in)sensitivity to the negative island is due to only the former in fact undergoing overt wh-movement.

Third, Chinese is also distinguished from Korean in light of wh-island effects. When two wh-phrases occur in the island-forming question complement of 'know' predicate (which is marked with the two brackets [ ] below), in Chinese one of them can take matrix scope, as in (36a), whereas wh-phrases in a 'whether' (i.e., shi-bu-shi) clause need to be d-linked, as in $(36 \mathrm{~b}, \mathrm{c})$. In Korean this type of wh-scoping is not allowed, as in (37).

(36) a. Zhangsan zhidao [shei mai-le shenme]?

Zhangsan know who buy-Perf what

'(Lit.) Zhangsan knows who bought what?' (Huang, 1982)

(i) Who does Zhangsan know bought what?

(ii) What does Zhangsan know who bought?

b. ??Zhangsan zhidao [shei shi-bu-shi mai-le \#shenme]?

Zhangsan know who be-not-be buy-Perf what

c. Zhangsan zhidao [na-ge ren shi-bu-shimai-le na-ge dongxi]?10)

Zhangsan know which person be-not-be buy-Perf which thing

'(Lit.) Who does Zhangsan know whether he bought what/which?'

(37) Cheli-nun [nwu-ka mwue-1 mek-ess-\{-nka, -nci\}]

Cheli-Top who-Nom what-Acc eat-Pst-upQ/upQ

alko iss-\{na, *no\}?

$(\mathrm{pQ}=$ Polar $\mathbf{Q}$-marker;

know be-pQ/*whQ upQ = Polar/Wh Q-marker)

'Lit. Cheli knows who ate what?'

(i) *Who does Cheli know ate what?

(ii) *What does Cheli know ate bought?

10) The matrix scope of na-ge ren 'which person' prior to shi-bu-shi in this example is obligatory. 
In addition, a single wh-phrase in the question complement of 'know' predicate takes embedded scope in Chinese and Korean alike, but the single wh-phrase in the whether clause with shi-bu-shi 'be-not-be' of Chinese needs to be d-linked:

(38) a. ni zhidao Zhangsan mai-le shenme?

You know Zhangsan buy-Perf what

'Lit. You know what Zhangsan bought?'

(i) 'Do you know what Zhangsan bought?'

(ii) '*What do you know whether Zhangsan bought?'

b. ??ni zhidao Zhangsan shi-bu-shi mai-le shenme?

You know Zhangsan be-not-be buy-Perf what

'Lit. you know whether Zhangsan bought something/\#what?'

'??What do you know whether Zhangsan bought?'

(39) ni-nun [Cheli-ka mwue-1 sa-ss-nu-\{-nka, -nci\}] a $\{$-na, *-no\}// you-Top Cheli-Nom what-Acc buy-Pst-upQ/upQ know-pQ/*whQ sa-ss-nunko] a-na?

buy-Pst-whQ know-pQ

'(Lit.) Do you know where Cheli went?'

In keeping with the thesis that wh-indeterminates in Chinese undergo overt wh-movement, we propose an across-the-board (ATB) movement analysis for them in bare wh-conditionals. In this analysis, clause-internal wh-phrases in the antecedent and the consequent clauses undergo overt $w h$-movement to their clausal peripheries and are then conjoined together via External Remerge (de Vries 2009, Park 2010). This accounts for the mandatorily co-varying phenomenon in Chinese bare wh-conditionals. (See also Bruening and Tran 2006, who also take an overt wh-movement analysis of bare wh-conditionals in Vietnamese, arguing that the wh-phrase undergoes sideward movement from a position in the consequent clause to another position in the antecedent clause.)

(40) Basic schema for wh-conditionals in Chinese: [adverbial clause $\cdots$ wh $\cdots$ ] [matrix clause $\cdots{ }^{\vee}$ wh/*ec/*definite $\mathrm{NP} \cdots$.] 
(41)

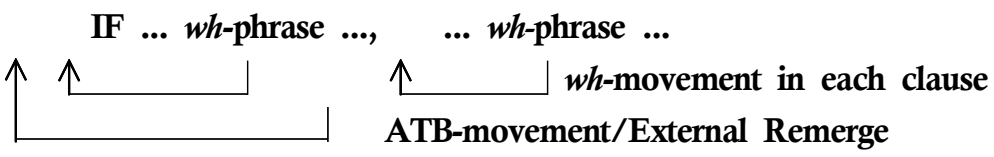

The overt wh-movement analysis has the following advantages. First, it accounts for why in bare wh-conditionals of Chinese, only wh-indeterminates/phrases, but not lexical indefinite expressions allow for co-variant interpretation. This is because the former, but not the latter, are required to undergo overt wh-movement in this language.

Second, it accounts for the fact that Chinese wh-conditionals do not display the so-called Double Island Effects, as Cheung (2007) reports (cf. Cheung, 2006). Chinese wh-phrases in either clause of wh-conditionals can appear in islands without giving rise to island violations (the islands are indicated by '[ ]' below), as shown in (42) and (43). Those in the Korean counterparts behave in a parallel fashion, as in (44).

(42) Complex NP

a. ni xihuan [shei xie de shu], women jiu qing shei lai. you like who write $\mathrm{DE}$ book we then invite who come 'Whoever $\mathrm{x}$ is s.t. you like the book written by $\mathrm{x}$, we will invite $\mathrm{x}$.'

b. ni xihuan shei, women jiu mai [shei xie de shu]. you like who we then buy who write de book 'Whoever $\mathrm{x}$ is s.t. you like $\mathrm{x}$, we'll buy the book written by $\mathrm{x}$.'

(43) Adjunct

a. ni [yinwei shei likai er shangxin], wo jiu piping shei. you because who leave thus sad I then criticize who 'Whoever $\mathrm{x}$ is s.t. you are sad because of x's leaving, I'll criticize $\mathrm{x}$.' b. ni taoyan shei, wo jiu [yinwei shei likai er gaoxing]. you dislike who I then because who leave thus happy 'Whoever $\mathrm{x}$ is s.t. you dislike $\mathrm{x}$, I'll be happy because of $\mathrm{x}$ 's leaving.' (from Cheung 2007) 
(44) a. John-i [nwu-ka ton-ul hwumchi-ess-ta-nun] somwun-ul tulu-myen, J.-Nom who-Nom money-Acc stole-Rel rumor-Acc hear-if Mary-ka ka-se e/ku-lul cheyphoha-n-ta.

M.-Nom go-and he-Acc arrest-Pre-Dcl

'If John hears the rumor that someone stole money, Mary goes to arrest that person.'

b. John-i nwukwu-lul uysimha-myen, Mary-nun [e/ku-ka ton-ul J.-Nom who-Acc suspect-if M.-Top he-Nom money-Acc hwumchi-ess-ta-nun somwun-ul] mit-nun-ta. stole-Rel rumor-Acc believe-Pre-Dcl

'If John suspects someone, Mary believes the rumor that that person stole money.'

It is known, however, that the Double Island Effects do show up, in the parasitic gap (PG) construction of English like (45a) versus (45b):

(45) a. This is the $\operatorname{man}_{\mathrm{i}}$ John interviewed $t_{\mathrm{i}}$ [PP before [CP telling [you to meet $\mathrm{e}_{\mathrm{i}}$ ]]]

b. *This is the man who $\mathrm{I}_{\mathrm{i}}$ decided to interview $\mathrm{t}_{\mathrm{i}}$ [PP $_{\mathrm{PP}}$ without [CP calling you

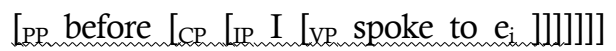

We attribute the difference in the presence vs. absence of the Double Island Effects between English PG constructions and Chinese wh-conditionals to the head vs. tail pronunciation of the chain. Since wh-movement in Chinese unlike its counterpart in English involves overt displacement but tail pronunciation, island effects do not arise for wh-arguments in Chinese bare wh-conditionals.

A third advantage is that the overt movement analysis can capture the argument vs. adjunct difference. Adjunct $w h$-movement in this construction incurs an island violation due to the ECP (Lasnik and Saito 1984, 1992), as in (46) versus (47). Even tail pronunciation (which only rescues Subjacency effects) cannot salvage movement of a wh-adjunct from an island.

(46) ni weishenme gaoxing, wo jiu weishenme shangxin. you why happy, I then why sad 'For whatever reason $\mathrm{x}$ such that you are happy for $\mathrm{x}$, I'm sad for $\mathrm{x}$.' 
(47) a. *ni xihuan [weishenme xie de shu], womenjiu weishenme xie shu. you like why write DE book we then why write book '(Lit.) Whatever reason $\mathrm{x}$ s.t. you like the book written for $\mathrm{x}$, we will write books for $\mathrm{x}$. '

b. *ni [yinwei ta weishenme likai er shangxin], wo jiu weishenme gaoxing you because he why leave thus sad I then why happy '(Lit.) Whatever reason $\mathrm{x}$ s.t. you are sad because he left for $\mathrm{x}$, I will be happy for x.' (taken from Cheung, 2007)

\section{Korean vs Chinese in ATB Movement}

Since we take the ATB wh-movement approach to co-varying interpretations of wh-phrases in bare wh-conditionals of Chinese, it is worth investigating bare whconditionals in comparison to run-of-the-mill ATB constructions. First, both Korean and Chinese allow overt ATB-movement, as follows:

(48) etten soselka 1 -lul [[Cheli-ka $t_{1}$ cohaha]-ko [Yengi-ka $t_{1}$ silheha]]-ni? which novelist-Acc Ch.-Nom like-Conj Y.-Nom dislike-Q 'Which novelist does Cheli like and Yengi dislike?'

(49) [na-wei zuojia $]_{3}$ [\&P [TP1 Zhangsan xihuan $t_{3}$ ] [TP2 Lisi bu xihuan $\left.t_{3}\right]$ ]? which-CL writer Z. like L. neg. like

'Which writer does Zhangsan like but Lisi dislike?' (ATB question)

The sensitivity to island contexts in the following examples renders supporting evidence showing that ATB extraction in Korean or Chinese can be an instance of overt movement:

(50) *[enu cengchiin $\left.{ }_{1}-\mathrm{ul}\right]$ [[Cheli-ka [ $\mathrm{t}_{1}$ kongkyekha-n chayk-ul] cohaha-ko] which politician-Acc Ch.-Nom attack-Rel book-Acc like-Conj

[Yengi-ka [ $t_{1}$ onghoha-nun chayk-ul] silheha]]-ni?

Y.-Nom advocate-Rel book-Acc dislike-Q

'Which politician is it such that Cheli likes a book that attacks him/her and Yengi dislikes a book that advocates him/her?' 
(51) *na-wei zuojia 1 Z Zhangsan xihuan [ $t_{1}$ xie ] de shu, which-CL writer $Z$. like write De book

Lisi bu xihuan [ $t_{1}$ xie ] de shu ]?

L. neg. like write De book

'For which writer $\mathrm{x}$, such that Zhangsan likes the books that $\mathrm{x}$ wrote but Lisi dislikes the books that $\mathrm{x}$ wrote?'

However, the two languages diverge in terms of the syntactic operation involved. Korean relies on scrambling to extract the shared element from the two conjuncts. In contrast, Chinese relies on topicalization to do so (Pan 2011). This contrast is evident, given the fact that unlike in Korean, the ATB-extracted element needs to be topicalized, thus needing to be d-linked.

(52) mwues ${ }_{1}$-ul [[Cheli-ka $t_{1}$ cohaha]-ko [Yengi-ka $t_{1}$ silheha]]-ni?

what-Acc Ch.-Nom like-Conj Y.-Nom dislike-Q

'What does Cheli like and Yengi dislike?'

(53) *[shenme $]_{3}\left[\right.$ \&P [TP1 Zhangsan xihuan $\left.t_{3}\right]\left[\right.$ TP2 Lisi bu xihuan $\left.\left.t_{3}\right]\right]$ ? what $Z$. like $\quad$ L. neg. like

'Which writer does Zhangsan like but Lisi dislike?'

To boot, Chinese and Korean differ in (non)-existence of 'non-identity' for the ATB-moved element. For instance, in English the wh-element where extracted from the two conjuncts can be interpreted sloppily as denoting two different cities:

(54) a. Where did Mary spend her vacation and Bill decide to live?

(adapted from Munn, 1993, 1999)

b. Mary spent her vacation in Paris and Bill decided to live in Toronto.

The same pattern of interpretation as in English obtains in Korean (55). Unlike in English and Korean, in Chinese the ATB-moved element nanei-ge chengshi 'which city' in (56a) does not allow for sloppy interpretation, resisting the answer in (56b):

(55) [enu tosi-eyse], [[Cheli-ka hyuka-lul ponay-ko sipheha-ko], which city-in Ch.-Nom vacation-Acc spend-to want-Conj [Yengi-ka unthoy hwu-ey sal-ki-lo kyelsimha-yss]]-ni? 
Y.-Nom retirement after live-to decide-Pst-Q

'What city does Cheli want to spend his vacation in and Yengi want to live in?'

(56) a. nanei-ge chengshi, Zhangsan xiang qu dujia, which-CL city $Z$. want go vacation

Lisi xiang qu dingju?

L. want go live

'Which city does Zhangsan want to spend his vacation in (but) Lisi want to live in?'

b. \# Zhangsan xiang qu Bali, Lisi xiang qu Lundun.

Z. want go Paris L. want go London

'Zhangsan wants to go to Paris; Lisi wants to go to London.'

With this background on ATB movement, we go on to compare the two wh-phrases in-situ in coordinate clause with those in bare wh-conditionals in Chinese. As noted by Pan (2011), unlike the latter as in (58), the former as in (57) do not co-vary.

(57) Zhangsan chi shenme, Lisi chi shenme?

$Z$. eat what L. eat what

(i) 'What does Zhangsan eat; and what does Lisi eat?'

(Parallel question reading)

(ii) ?? 'For every $\mathrm{x}, \mathrm{x}$ a thing, such that (if) Zhangsan eats $\mathrm{x}$, (then) Lisi eats $\mathrm{x}$.'

(Conditional construal)

(58) (ruguo) Zhangsan chi shenme, Lisi *(jiu) chi shenme?

if $\quad Z$ eat what $L$. then eat what

(i) * 'What does Zhangsan eat; and what does Lisi eat?'

(Parallel questions reading)

(ii) 'For every $\mathrm{x}, \mathrm{x}$ a thing, such that (if) Zhangsan eats $\mathrm{x}$, then Lisi eats $\mathrm{x}$.'

(Conditional construal)

This contrast points to the fact that the two wh-phrases in coordinate structure as in (57) are referentially independent, while those in subordinate structure as in (58) are referentially dependent. We attribute this contrast between coordinate and subordinate structure in referential (in)dependency to the different type of the covert conjunction that External Remerge employs to unify the two wh-phrases overtly 
extracted from the two different clauses in Chinese. On the one hand, the coordinate structure as in (57) uses the coordinate type of covert conjunction which can unify two sloppily interpreted wh-phrases. By contrast, the subordinate structure as in (58) uses the subordinate type of covert conjunction that can only unify two identically interpreted wh-phrases.

Note that in Korean where overt wh-movement is lacking, conditionals do not allow for co-varying interpretation between the two wh-phrases in the antecedent and the consequent clauses. ${ }^{11)}$ However, note that unlike in (55) where the ATBmoved wh-phrases from the two clauses of coordinate structure is construed sloppily, its counterpart from the conditional of subordinate structure as in (59b) only allows non-sloppy, identical interpretation:

(59) a. Cheli-ka mwues-ul sao-myen, Yengi-ka (*mwues-1ul) socwung-hi pokwanha-ni? Ch.-Nom what-Acc buy-if Y.-Nom what-Acc carefully keep-Q '(Lit) If Cheli buys what, Yengi keep what?'

b. mwues 1 -ul, [Cheli-ka $t_{1}$ sao-myen], [Yengi-ka $t_{1}$ socwunghi pokwanha]-ni? what-Acc Ch.-Nom buy-if Y.-Nom carefully keep-Q 'What does Yengi keep if Cheli buys (it)?'

Before leaving the section, we point out the parallelism between bare wh-conditionals in Chinese and subject PG constructions in English.12) We repeat the schematic structure of bare wh-conditionals in (60).

(60) Post-ATB-moved bare wh-conditionals in Chinese:

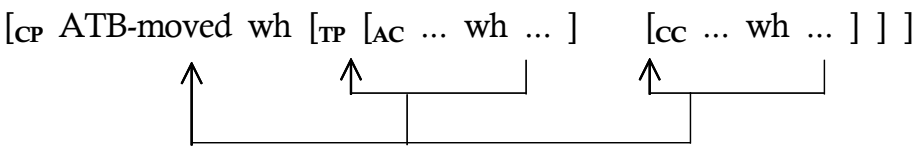

11) Alternatively, a possible analysis for the absence of the co-varying construal between wh-indeterminates in Korean conditionals is that Korean conditionals are assimilated to Chinese ruguo or yaoshi conditionals, but not to Chinese bare conditionals. Such semantically-functioning operators as -tamyen 'if' in Korean and their counterparts ruguo and yaoshi in Chinese in these conditionals serve as a barrier precluding $w h$-indeterminates from undergoing overt wh-movement that is in need for the co-varying interpretation between them.

12) One of the reviewers suspects that the Korean example in (59b) has the structure in (60). Notice, however, that Korean ATB movement of a wh-indeterminate expression is an instance of scrambling, as stated above, while the Chinese counterpart is an instance of movement to the licensing position, most likely the SPEC of CP. 
The example with a PG in the subject in English, taken from Chomsky (1986), is represented schematically, as in (61):

(61) Subject PGs in English:

He's a man that [anyone who tells people to talk to $\mathrm{pg}$ ] usually likes $\mathrm{rg}$ ?

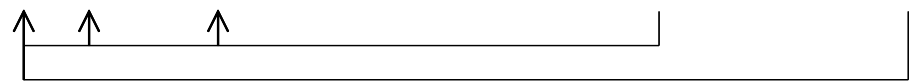

The parallelism between the two constructions at issue is striking. The two chains are combined together. Since the two chains are not in coordinate structure, the ATB-moved, shared element from them is referentially identical. Of course, the difference between them is that unlike in Chinese bare wh-conditionals, both the PG as well as the real gap ( $\mathrm{rg}$ ) in English PG constructions is realized as null because of the tail copy deletion.

We also note the parallelism between bare wh-conditionals in Chinese and correlatives in Hindi:

(62) Post-ATB-moved bare wh-conditionals in Chinese:

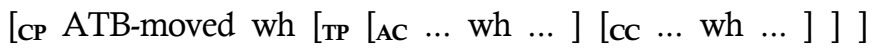

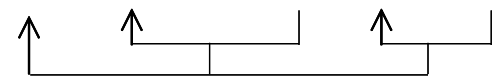

(63) Correlatives in Hindi:

[jo lərki $\quad k^{h}$ eri $\left.h \varepsilon\right] \quad$ [vo $\uparrow$

which girl.F.Sg standing.F.Sg be.Prs.3.Sg that tall.F.Sg be.Pres.3.Sg 'Which girl is standing, that/she is tall' (from Dayal 1996)

In Hindi, wh-elements take the wh-in-situ strategy. Because of the absence of overt wh-movement in this language, if the wh-element instead of the demonstrative occurred in the matrix clause, it would not undergo ATB movement with the relativizer which girl at the periphery of the correlative clause. Despite this difference, Hindi correlatives have great resemblance to Chinese wh-conditionals, in that the demonstrative in the matrix clause as an E-type pronoun co-varies with the wh-phrase at the periphery of the correlative clause. It is to be underscored that overt wh-movement or wh-in-situ in the matrix clause is a critical factor in deriving the Chinese type of wh-conditionals or Hindi type of correlatives. ${ }^{13)}$ 


\section{Chinese vs. Korean Regarding Indeterminates}

We would like to note that Korean and Chinese diverge as regards indeterminates. First, Chinese has indefinites that have the exactly same form as interrogatives (i.e., wh-indefinites), thus both of them being called indeterminates. For example, shenme 'what/something' in Chinese are used either as run-of-the-mill indefinites or whindefinites. By contrast, Korean/Japanese distinguish wh-indefinites and non-whindefinites. In particular, in Korean the latter can be marked explicitly by attaching a certain affix (i.e., $n$-ka) to the interrogative form. Thus, in Korean mwues 'what' and mwues-nka 'something' are distinguished in form, though the former can also be used as indefinites.

Bruening (2007, p. 159) compares these two types of indeterminates in a number of languages and presents the following generalization: "(i) Chinese type of indeterminates that do not include additional morphology for non-wh-indefinites are precluded from taking wide scope and in fact usually take only narrowest scope. However, (ii) Korean/Japanese type of indeterminates that do include additional morphology for non-wh-indefinites may take wide scope and may even be interpreted referentially (as specific indefinites)," the quoted part of which is taken from Yun (2019).

On top of the difference between Chinese and Korean in the morphological composition of indeterminates, the two languages differ in regard to the availability of morphological case marker on them. In Korean, the morphological case marker immediately empowers the indeterminate to readily serve as a wh/non-wh indefinite, thereby the Novelty Condition disallowing the second occurrence of the case-marked indeterminate from co-varying with its first occurrence.

By contrast, in Chinese the absence of morphological case marker cannot readily enable the indeterminate to serve as a wh/non-wh indefinite. Thus, both the first and the second occurrence of the case-less, bare indeterminate await another

13) In English, the following examples which correspond to bare wh-conditionas in Chinese are a little degraded but acceptable (The judgment of them being attributed to Michael Barrie (per comm.)).

(i) a.?I wonder which book if you read, you will understand right away.

b. ?I wonder what if you pick, you'll get.

Though we do not have a good answer to why they are degraded (probably because "what" moves out of the adjunct island formed by the subordinator 'if", the availability of overt wh-movement in English predicts that the wh-element can be extracted in the ATB fashion from the antecedent and the consequent clauses of conditionals in this language. 
licensing device such as overt wh-movement.

\section{Conclusion}

In this paper we have argued that indeterminates in bare wh-conditionals of Chinese are not run-of-the-mill indefinites, but wh-phrases. Thus, instead of being licensed via unselective binding by the universal operator as argued in Cheng and Huang (1996), they undergo overt ATB-fashion wh-movement, ultimately its head copy being not realized (but its tail copy being realized). We attributed the co-varying interpretation between the two wh-phrases to the property of the covert form of subordinate conjunction that can only unify identically interpreted conjoined elements. By contrast, Korean wh-phrases do not rely on overt wh-movement, but on Agree with the $\mathrm{Q}$ marker for their licensing. Thus in the Korean counterparts of bare wh-conditionals, the wh-phrase in the antecedent clause is referred back to by the anaphoric expression that serves an E-type pronoun-like function, such as a demonstrative (plus the wh-indefinite) or a null argument. But unlike that in Chinese, the wh-phrase in Korean cannot serve as an anaphoric expression. It is to be stressed that but for the lack of overt wh-movement, the two wh-phrase in Korean cannot be anaphorically related via ATB wh-movement.

\section{References}

Abe, J. (2017). Wh-in-situ licensing. Unpublished manuscript.

Aoun, J., \& Li, Y-H. A. (1993). Syntax of scope. Cambridge: MIT Press.

Beck, S. (1997). Wh-constructions and transparent logical form. Neuphilologische Fakultat Tubingen.

Beck, S., \& Kim, S-S. (1997). On wh- and operator scope in Korean. Journal of East Asian Linguistics, 6(4), 339-384.

Bruening, B. (2007). Wh-in-situ does not correlate with wh-indefinites or question particles. Linguistic Inquiry, 38, 139-166.

Bruening, B., \& Tran, T. (2006). Wh-conditionals in Vietnamese and Chinese: Against unselective binding. In Z. Anti'c et al. (Eds.), Berkeley Linguistics Society (BLC), 3, 49-60. doi:http://dx.doi.org/10.3765/bls.v32i1.3440.

Cheng, L. L-S. \& Huang, C-T. J. (1996). Two types of donkey sentences. Natural Language Semantics 4(2), 121-163. doi:10.1007/BF00355411. 
Cheung, C. C-H. (2006). The syntax and semantics of bare conditionals in Chinese. In E. Puig-Waldmuller (Ed.), Sinn und Bedeutung (SuB) 11, 150-164.

Cheung, C. C-H. (2007). Move or not move? A case study of wh-conditionals in Mandarin. In E. Elfner and M. Walkow (Eds.), Proceedings of the 37th Meeting of the North East Linguistic Society (NELS 37), Vol. 1, 153-164. Amherst: GLSA.

Choe, J. W. (1987). LF-movement and pied-piping. Linguistic Inquiry, 18, 348-353.

Crain, S., \& Luo, Q-P. (2011). Identity and definiteness in Chinese wh-conditionals. In I. Reich et al. (Eds.), Proceedings of Sinn \& Bedeutung 15, pp. 165-179. Universaar - Saarland University Press: Saarbrücken, Germany.

Chierchia, G. (2000). Chinese conditionals and the theory of conditionals. Journal of East Asian Linguistics, 9(1), 1-54.

Dayal, V. (1996). Locality in WH quantification: Questions and relative clauses in hindi. (Studies in Linguistics and Philosophy, 62.) Dordrecht: Kluwer.

de Vries, M. (2009). On multidominance and linearization. Biolinguistics, 3, 344-403.

$\mathrm{Gu}, \mathrm{C}$. (2009). Maximalization and the definite reading in mandarin wh-conditionals. Paper presented at the $40^{\text {th }}$ Annual Meeting of the North East Linguistic Society (NELS 40), November 13-15, 2009. Cambridge: MIT.

Heim, I. (1982). The semantics of definite and indefinite noun phrases (Ph. D. dissertation). University of Massachusetts at Amherst.

Huang, C-T. J. (1982). Logical relations in chinese and the theory of grammar. (Ph.D. dissertation.). MIT.

Huang, C-T. J. (2018). Analyticity and wh-conditionals as unselective binding par excellence. A handout read at BLCU in Peking, China.

Ko, H. (2005). Syntax of why-in-situ-Merge into [Spec,CP] in the overt syntax. Natural Language and Linguistic Theory, 23, 867-916.

Lasnik, H., \& Saito, M. (1984). On the nature of proper government. Linguistic Inquiry, 15, 235-289.

Lasnik, H., \& Saito, M. (1992). Move a: Conditions on its application and output. Cambridge, MA: MIT Press.

Leung, T-C. (2006). On the matching requirement in correlatives. Ms. USC.

Liu, M. (2016). Mandarin wh-conditionals as interrogative conditionals. Proceedings of SALT, 26, 814-835.

Liu, M. (2018b). Proposal-B: wh-conditionals as interrogative dependency. Varieties of Alternatives, 153-170.

Liu, M. (2018a). Proposal-A: wh-conditionals as interrogative conditionals. Varieties of Alternatives, 135-152.

Longobardi, G. (1987). Extraction from NP and the proper notion of head government. In Alessandra Giorgi and Giuseppe Longobardi (Eds.), The Syntax of Noun Phrases, pp. 57-112. Munn, A. (1993). Topics in the Syntax and Semantics of Coordinate Structures (Ph. D. dissertation), University of Maryland, College Park. 
Munn, A. (1999). On the identity requirement of ATB movement. Natural Language Semantics, 7, 421-425.

Nishigauchi, T. (1986). Quantification in synta (Ph. D. dissertation). University of Massachusetts. Nunes, J. (2004). Linearization of chains and sideward movement. Cambridge, MA: MTT Press.

Pan, V. J. (2011). ATB-topicalization in Mandarin Chinese: an intersective operator analysis. Linguistic Analysis, 37, 231-272.

Park, M-K. (2010). Derivation via external remerge and linearization in ATB, RNR and PG constructions of English. Korean Journal of Linguistics, 35, 613-634.

Park, M-K. (2019). Reconsidering null arguments in East Asian languages: Null arguments as anaphoric definites. Ms., Dongguk University.

Saito, M. (2017). Japanese wh-phrases as operators with unspecified quantificational force. Language and Linguistics, 18(1), 1-35.

Suh, C-M. (2008). Revisiting -ko-class Q markers WH-agreeing with wh-phrases in embedded sentences. In Y. H. Kim (Ed.), Syntax \& Semantics of Wh-Interrogatives, 133-178.

Tsai, W-t. D. (1994). On Economizing the theory of A-bar dependencies (Ph. D. dissertation). MIT. Yun, Jiwon. 2019. Meaning and prosody of wh-indeterminates in Korean. Linguistic Inquiry 50, 630-647.

Watanabe, A. (1992). Subjacency and S-strucgture movement of wh-in-situ. Jouranl of East Asian Linguistics, 1(3), 255-291.

\section{Daeho Chung \\ Professor}

Department of English Language and Culture

Hanyang University

55 Hanyangdaehak-ro, Sangnok-gu, Ansan-si, Gyeonggi-do

E-mail: cdaeho@hanyang.ac.kr

Myung-Kwan Park

Professor

Division of English

Dongguk University

30, 1-gil, Phil-dong-ro, Jung-gu, Seoul 04620, Korea

E-mail: parkmk@dongguk.edu

Received: October 2, 2019

Revised version received: November 5, 2019

Accepted: December 26, 2019 